\title{
Effects of exercise on gas exchange in patients recovering from acute severe asthma
}

\author{
G E Packe, W Freeman, R M Cayton
}

\begin{abstract}
The effect of exercise on gas exchange was studied in 17 patients (seven male and 10 female) recovering in hospital from acute severe asthma. On admission the patients (mean age 26 (SD 8) years) had a mean peak expiratory flow (PEF) of $26.8 \%$ $(5 \cdot 7 \%)$ predicted, a mean arterial oxygen tension $\left(\mathrm{PaO}_{2}\right)$ of $8.63(1.26) \mathrm{kPa}$, and a mean alveolar-arterial oxygen difference $\left(\mathrm{A}-\mathrm{aDO}_{2}\right)$ of $5.98(1.34) \mathrm{kPa}$. Once resting symptoms had resolved (after $3.7(1.6)$ days) patients performed a constant load exercise test (100 watts for men, 75 watts for women) on a bicycle ergometer for five minutes. PEF was measured before exercise and at five minute intervals for 30 minutes after exercise. Blood gas tensions were measured on capillary blood before, during, and 10 minutes after exercise. Treatment was not interrupted for this study. Mean PEF at rest was $87.6 \%$ $(21 \cdot 1 \%)$ predicted and showed no significant change after exercise. Mean $\mathrm{PaO}_{2}$ was $13 \cdot 13(1 \cdot 37) \mathrm{kPa}$ before exercise; it showed no significant change during exercise $(13.93(1.34) \mathrm{kPa})$ or 10 minutes after exercise $(13.50(2 \cdot 15) \mathrm{kPa})$. Mean $\mathrm{A}-\mathrm{aDO}_{2}$ also showed no change, being 1.82 (1.31) $\mathrm{kPa}$ before exercise, $1.79(1.27) \mathrm{kPa}$ during exercise, and $2.53(0.93) \mathrm{kPa}$ after exercise. It is concluded that moderate exercise carried out shortly after treatment for acute severe asthma is unlikely to result in worsening gas exchange during or after exercise if resting PEF, $\mathrm{PaO}_{2}$ and $\mathrm{A}-\mathrm{aDO}_{2}$ have attained normal or near normal values.
\end{abstract}

Patients treated in hospital for acute asthma are usually monitored by serial assessment of symptoms, clinical examination, and measurement of airflow-usually peak expiratory flow (PEF). Patients are discharged from hospital when their symptoms have abated and their peak flow recordings are stable. On their return home their activity will increase; yet very little is known about the cardiorespiratory effects of exercise after treatment for an acute attack, and patients are seldom given advice on the level of activity they can safely engage in after discharge.

Although treatment in hospital for acute asthma usually results in prompt improvement of symptoms and PEF, ${ }^{1}$ residual disturbance of lung function may persist for weeks, probably as a consequence of persistent narrowing in peripheral airways. ${ }^{1}$ This results in ventilation- perfusion $\left(\dot{V}_{A} / \dot{Q}\right)$ imbalance, ${ }^{2}$ which, if severe, may cause hypoxaemia that persists weeks after the acute attack. ${ }^{3}$

Despite being symptom free at rest, patients recovering from acute asthma are more likely to have residual abnormalities of lung function than are symptom free patients whose asthma has been stable for some time. ${ }^{4}$ Such abnormalities might not be apparent at rest but could cause impaired gas exchange during exercise when the cardiorespiratory system is stressed.

The bronchoconstrictor effect of exercise in asthmatic patients has been studied in detail, ${ }^{5}$ but not in patients recently treated for a spontaneous attack of asthma. In such patients bronchoconstriction induced by exercise might aggravate pre-existing $\dot{V}_{A} / Q$ imbalance.

The aim of this study was to examine the effects of exercise on gas exchange, in patients recently treated in hospital for acute severe asthma, and to relate the changes seen during exercise to measurements of airflow and blood gas tensions recorded before exercise.

\section{Results}

PATIENTS

We studied 17 patients (seven male, 10 female) admitted to East Birmingham Hospital with acute severe asthma. Their mean age was 26 (SD 8) years. All patients were under the supervision of a respiratory physician. The diagnosis of asthma was based on clinical findings and a greater than $20 \%$ increase in PEF with treatment. We excluded patients under the age of 18 or over 50 , and those with a history of ischaemic heart disease or any other serious medical disorder. Informed consent was obtained from all patients before entry to the study, which was approved by the hospital ethical committee.

On admission, PEF and arterial blood gas measurements were recorded. All patients were treated initially with oxygen, $5 \mathrm{mg}$ salbutamol in $2 \mathrm{ml}$ normal saline via a jet nebuliser, $200 \mathrm{mg}$ intravenous hydrocortisone, and $40 \mathrm{mg}$ oral prednisolone. The fractional inspired oxygen concentration was adjusted to maintain the arterial oxygen tension $\left(\mathrm{PaO}_{2}\right)$ above $8 \mathrm{kPa}$. Patients who failed to respond to this regimen were given further doses of salbutamol and hydrocortisone and an infusion of aminophylline $(6 \mathrm{mg} / \mathrm{kg}$ loading dose followed by an infusion adjusted according to serum theophylline concentrations). Clinical condition and PEF were monitored closely. Treatment with six hourly nebulised salbutamol and intravenous hydrocortisone or oral prednisolone (or both) was continued until the \author{
Dr G E Packe, Department \\ Aberdeen Royal Infirmary, \\ Aberdeen AB9 2ZB \\ Accepted 13 October 1989 \\ Respiratory \\ Birmingham Hospital \\ G E Packe \\ W Freeman \\ R M Cayto
}


patient showed satisfactory clinical recovery and PEF was stable. The dose of prednisolone was then reduced, and treatment changed to inhaled medication via a metered dose aerosol (usually salbutamol $800-1200 \mu \mathrm{g}$ daily and beclomethasone dipropionate $400-1500 \mu \mathrm{g}$ daily.)

Patients' treatment was not interrupted during the course of the study.

\section{EXERCISE TEST}

Patients performed an exercise test once they were symptom free at rest and walking round the ward. The test took place between 11.00 and 12.00 am, usually three to six hours after the patients had had their last treatment. They were familiarised with the equipment before the test. With the external work load set at 100 watts for men and 75 watts for women, patients pedalled on an electromagnetically braked bicycle ergometer (Rodby Elektronik, Enhörna, Sweden) for five minutes at a steady rate of $60 \mathrm{rev} / \mathrm{min}$ (indicated by a tachometer).

\section{PHYSIOLOGICAL MEASUREMENTS}

PEF was measured before exercise and one, five, 15, 20, 25, and 30 minutes after exercise, a Wright peak flow meter being used. ${ }^{6}$ The best of three blows was recorded on each occasion. Predicted normal values for PEF were estimated from standard regression equations. ${ }^{7}$

Measurements were made by means of a computerised exercise testing system (P K Morgan Ltd, Rainham, Kent). Subjects breathed through a Hans Rudolph two way, non-rebreathing valve for three minutes before exercise and throughout exercise, wearing a nose clip. Seven minutes after completion of the exercise test patients were reconnected to the breathing circuit for a further five minutes while at rest so that gas exchange could be examined at a time when any exercise induced bronchoconstriction was likely to be maximal.

Inspired airflow was measured by a turbine ventilometer attached to the inspiratory port of the valve box. Expired gas passed via a 3 litre mixing chamber to a paramagnetic analyser (Morgan 252) and an infrared gas analyser (Morgan 801D) for measurement of the fractional concentration of oxygen and carbon dioxide in expired gas. The electrocardiogram was continuously displayed on an oscilloscope. Equipment was calibrated before each exercise test.

Signals from the turbine ventilometer, gas analysers, and oscilloscope were fed to a microcomputer. Values for heart rate $\left(f_{c}\right)$, breathing frequency $\left(f_{b r}\right)$, tidal volume $(V T)$, minute ventilation $(\dot{\mathrm{VE}})$, oxygen uptake $\left(\dot{\mathrm{Vo}}_{2}\right)$, and carbon dioxide production $\left(\dot{\mathrm{V}} \mathrm{CO}_{2}\right)$ and the respiratory exchange ratio $(\mathrm{R})$ were printed at 15 second intervals. Values for $\mathrm{Vo}_{2}$ were automatically plotted on a visual display unit before, during, and after exercise. Predicted values for maximum $\mathrm{V}_{2}$ were derived from the regression equations of Jones and Campbell. ${ }^{8}$

A sample of arterialised capillary blood was obtained from an earlobe ${ }^{9}$ before exercise, during the last 15 seconds of exercise, and 10 minutes after exercise. Blood samples were taken when the displayed value for $\mathrm{Vo}_{2}$ had reached a plateau, indicating that steady state conditions had been reached. Blood gas measurements were made with a Corning $\mathbf{1 7 0}$ analyser. Comparison of gas tension measurements on arterialised capillary blood and those made previously on arterial blood from 30 subjects routinely attending the respiratory function laboratory showed a mean difference in $\mathrm{PaO}_{2}$ of $-0.06 \mathrm{kPa}$ (95\% confidence limits $-0.91,+0.79 \mathrm{kPa})$ and in carbon dioxide tension $\left(\mathrm{PaCO}_{2}\right)$ of $0.05 \mathrm{kPa}(95 \%$ confidence limits $-0.44,+0.54 \mathrm{kPa}$ ).

Ideal alveolar oxygen tension $\left(\mathrm{PAO}_{2}\right)$ was calculated from the blood gas data collected when patients were first admitted to hospital on the basis of the shortened form of the alveolar gas equation $^{10}$ :

$$
\mathrm{PaO}_{2}=\mathrm{FIO}_{2}\left(\mathrm{~PB}-\mathrm{PH}_{2} \mathrm{O}\right)-\frac{\mathrm{PaCO}_{2}}{\mathrm{R}},
$$

where $\mathrm{FIO}_{2}$ is the inspired oxygen concentration, $\mathrm{PB}$ is barometric pressure, $\mathrm{PH}_{2} \mathrm{O}$ is saturated water vapour pressure at body temperature $\left(6.3 \mathrm{kPa}\right.$ at $\left.37^{\circ} \mathrm{C}\right)$, and $R$ is assumed to be $0 \cdot 8$.

The full alveolar gas equation was used to calculate $\mathrm{PaO}_{2}$ from the blood gas measurements on arterialised capillary blood, ${ }^{11}$ with the $R$ value recorded at the time blood samples were taken:

$$
\begin{aligned}
\mathrm{PaO}_{2}=\mathrm{FIO}_{2} \times(\mathrm{PB}- & \left.\mathrm{PH}_{2} \mathrm{O}\right)-\frac{\mathrm{PaCO}_{2}}{\mathrm{R}}+ \\
& +\frac{\mathrm{PaCO}_{2}}{\mathrm{R}} \times \mathrm{FIO}_{2}(\mathrm{I}-\mathrm{R}) .
\end{aligned}
$$

The dead space: tidal volume ratio $(\mathrm{VD} / \mathrm{VT})$ was calculated from the modified Bohr equation $^{12}$ :

$$
\frac{\mathrm{VD}}{\mathrm{VT}}=\frac{\left(\mathrm{PaCO}_{2}-\mathrm{PECO}_{2}\right)}{\mathrm{PaCO}_{2}}-\frac{\mathrm{VDapp}_{\mathrm{ap}}}{\mathrm{VT}}
$$

where $\mathrm{PECO}_{2}$ is mixed expired carbon dioxide pressure, and $\mathrm{VD}_{\mathrm{app}}$ is the dead space of the apparatus (mouthpiece and valve box, $65 \mathrm{ml}$ ).

\section{STATISTICAL METHODS}

Results are expressed as the means with standard deviations in parentheses. Mean values were compared by Student's paired $t$ test.

\section{Results}

On admission all patients had considerable bronchoconstriction with hypoxaemia and an increase in the alveolar-arterial oxygen dif-

\begin{tabular}{|c|c|c|c|c|}
\hline & Admission & $\begin{array}{l}\text { Before } \\
\text { exercise }\end{array}$ & $\begin{array}{l}\text { During } \\
\text { exercise }\end{array}$ & $\begin{array}{l}\text { After } \\
\text { exercise } \neq\end{array}$ \\
\hline $\begin{array}{l}\mathrm{PEF} \\
\mathrm{PaO}_{2} \\
\mathrm{~A}-\mathrm{aDO}_{2} \\
\mathrm{PaCO}_{2}\end{array}$ & $\begin{array}{c}26.8(5.7) \\
8.63(1.26)^{\star} \\
5.98(1.34)^{\star} \\
4.38(0.83)\end{array}$ & $\begin{array}{c}87.6(21 \cdot 1) \\
13.13(1.37) \\
1.82(1.31) \\
4.24(0.35)\end{array}$ & $\begin{array}{c}89.4(20.8) \dagger \\
13.93(1.34) \\
1.79(1.27) \\
4.24(0.58)\end{array}$ & $\begin{array}{c}86.1(22.3) \\
13.50(2.15) \\
2.53(0.93) \\
3.78(0.52)\end{array}$ \\
\hline
\end{tabular}
ference $\left(\mathrm{A}-\mathrm{aDO}_{2}\right)$-see table 1 and figure. Four

Table 1 Mean (SD) values for gas exchange before, during and after exercise

$\star_{\mathrm{n}}=13$.

$t_{\mathrm{n}}=9$.

tOne minute after exercise.

PEF-peak expiratory flow; $\mathrm{PaO}_{2}$-arterial oxygen tension; $\mathrm{A}$-aDo 2 -alveolar-arterial oxygen difference; $\mathrm{PaCO}_{2}$-arterial carbon dioxide tension. 

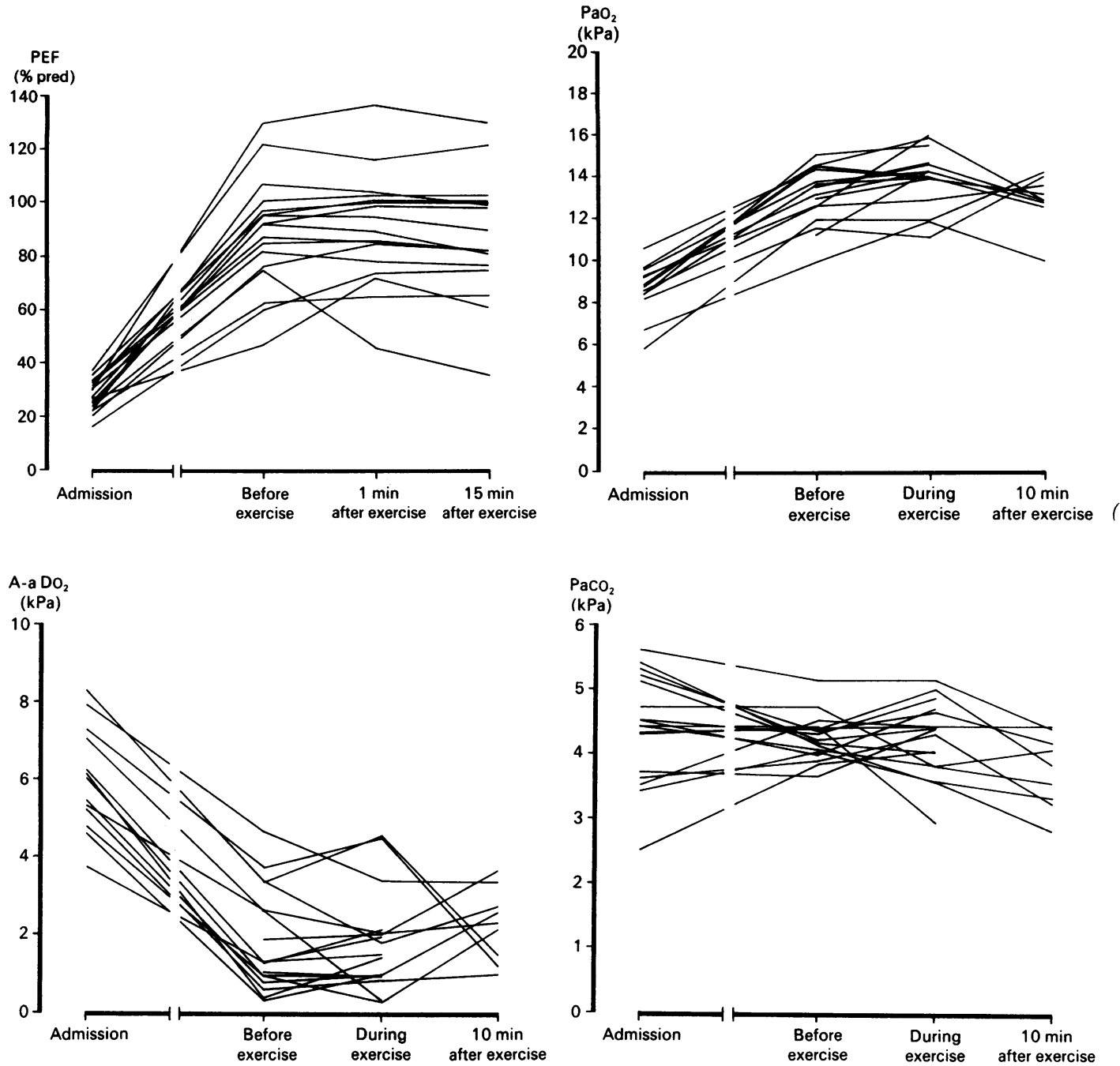

Data for individual patients on admission and before, during, and after exercise: (a) peak expiratory flow (PEF); (b) arterial oxygen tension $\left(\mathrm{PaO}_{2}\right) ;(c)$ alveolar-arterial oxygen difference $\left(A-a \mathrm{DO}_{2}\right)$; arterial carbon dioxide tension $\left(\mathrm{PaCO}_{2}\right)$.

patients had blood gases measured when they were breathing high concentration oxygen. As this will raise $\mathrm{PaO}_{2}$ and $\mathrm{A}-\mathrm{aDo}_{2},{ }^{15}$ mean values for $\mathrm{PaO}_{2}$ and $\mathrm{A}-\mathrm{aDO}_{2}$ at the time of admission refer only to the 13 patients breathing air.

The mean (SD) interval between admission and the exercise test was 3.7 (1.6) days. Before exercise mean PEF showed a significant increase from the value at admission $(p<0.001)$, all but three subjects reaching a value greater than $70 \%$ predicted before exercise. Mean $\mathrm{PaO}_{2}$ had increased and $\mathrm{A}-\mathrm{aDO}_{2}$ had decreased ( $p<0.001$ for both) to within the range predicted for normal subjects at rest. ${ }^{14} 15$

The three subjects with persisting airflow obstruction had normal blood gas measurements at the time of exercise. Persisting airflow obstruction was also present when they were later reviewed.

During exercise mean $\mathrm{PaO}_{2}$ or $\mathrm{A}-\mathrm{aDO}_{2}$ remained within the limits expected for normal subjects, ${ }^{15}$ with no change from the pre-exercise values. Mean PEF one minute after exercise was similar to mean PEF before exercise, and there was no significant change in mean PEF at any time over the 30 minutes after exercise.

Blood gas data could be obtained in only nine patients after exercise because of difficulty in obtaining a third capillary blood sample from the earlobe. There was no change in mean $\mathrm{PaO}_{2}$ or $\mathrm{A}-\mathrm{aDO} \mathrm{O}_{2} 10$ minutes after exercise from the values recorded during exercise.

Other measurements made at rest and recorded during exercise are shown in table 2. Mean VD/VT decreased during exercise but remained within the normal range. Negative values for VD/VT were recorded during exercise in three patients; the mean exercise value for $\mathrm{VD} / \mathrm{VT}$ was calculated from the results in the

Table 2 Mean (SD) values for cardiorespiratory data before, during and after exercise

\begin{tabular}{|c|c|c|c|}
\hline & Rest & $\begin{array}{l}\text { During } \\
\text { exercise }\end{array}$ & $\begin{array}{l}\text { After } \\
\text { exercise }\end{array}$ \\
\hline 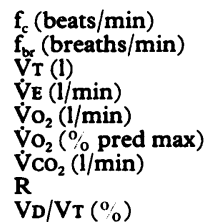 & $\begin{array}{c}86(14) \\
16 \cdot 8(4 \cdot 2) \\
0.70(0.36) \\
10.9(2 \cdot 3) \\
0 \cdot 29(0.08) \\
11 \cdot 2(3.9) \\
0.25(0.07) \\
0.88(0.13) \\
25 \cdot 6(9.0)\end{array}$ & $\begin{array}{l}158(18) \\
24 \cdot 4(6 \cdot 9) \\
1.02(0.86) \\
45.0(5.9) \\
1.44(0.32) \\
54 \cdot 1(7.4) \\
1.50(0 \cdot 25) \\
1.06(0.07) \\
7.3(5 \cdot 6)^{\star}\end{array}$ & $\begin{array}{l}103(17) \\
16.0(4.8) \\
0.94(0.45) \\
13.33(2.43) \\
0.33(0.10) \\
12.68(3.69) \\
0.30(0.09) \\
0.88(0.16) \\
27.9(0.15) \dagger\end{array}$ \\
\hline
\end{tabular}

$\star_{\mathrm{n}}=14$.

tn $=9$.

$f_{c}$-heart rate; $f_{b r}$-respiratory rate; VT-tidal volume; $\dot{V}_{E}-$ minute ventilation; $\mathrm{VO}_{2}-$ oxygen uptake; $\mathrm{VCO}_{2}-$ carbon dioxide production; $\mathrm{VD}-$ dead space. 
remaining 14 subjects. Mean oxygen uptake during the test was $54 \cdot 1 \%$ of the predicted maximum $\dot{\mathrm{VO}}_{2}$. Ten minutes after exercise measurements had returned to the levels observed before exercise.

\section{Discussion}

On admission to hospital with acute asthma all the patients had substantial airflow obstruction and evidence of $\dot{V}_{A} / Q$ imbalance with a low $\mathrm{PaO}_{2}$ and an increased $\mathrm{A}-\mathrm{aDO}_{2}$. Intensive treatment was instituted and in most patients these measurements had reverted to normal before exercise-within a few days of admission. The rapid recovery seen in most subjects was probably a reflection of their relative youth; younger asthmatic patients usually respond faster to treatment than do older patients. ${ }^{16}$

After treatment for acute severe asthma appreciable $\dot{V}_{A} / Q$ imbalance may persist despite normal spirometric and blood gas measurements, $\mathrm{PaO}_{2}$ being maintained by an increase in cardiac output. ${ }^{17}$ In these circumstances the increase in blood flow and the ventilation that accompanies exercise might be expected to cause worsening gas exchange, especially if ventilation increased to areas of the lung that were already overventilated with respect to their blood flow, and if blood flow increased to poorly ventilated areas of lung. Nevertheless, when our patients underwent exercise there was no fall in $\mathrm{PaO}_{2}$ or increase in $\mathrm{A}-\mathrm{aDO}_{2}$, indicating that any possible residual $\dot{V}_{A} / \dot{Q}$ imbalance was of minor degree and insufficient to cause any worsening in gas exchange. These findings are compatible with those of studies in patients with stable asthma, which have generally shown no change or a minor improvement in gas exchange during exercise. ${ }^{181920}$

A deterioration in gas exchange might have been found in patients who had been treated less vigorously or who had appreciable residual airflow obstruction. Three of our patients had moderate airflow obstruction before exercise but had a normal $\mathrm{PaO}_{2}$ before, during, and after exercise. In these subjects $\mathrm{PaO}_{2}$ may have been maintained by a compensatory increase in cardiac output ${ }^{17}$ or by reflex vasoconstriction of pulmonary blood vessels in hypoxic areas of lung. ${ }^{21}$ Such compensatory mechanisms might fail when severe airflow obstruction is present; it is noteworthy that one of the five asthmatic patients studied by Anderson et al $^{18}$ had a preexercise PEF of about $30 \%$ predicted and a substantial fall in $\mathrm{PaO}_{2}$ during submaximal exercise, though $\mathrm{PaO}_{2}$ rapidly recovered after exercise.

The intention of the present study was to observe the effect of exercise in asthmatic patients receiving standard treatment for acute asthma, so treatment was not interrupted. As a result the bronchoconstrictor response to exercise normally seen in patients with hyperresponsive airways was suppressed and consequently there was no deterioration in gas exchange after exercise.

The effect of exercise on gas exchange after treatment had been withdrawn was studied in six adults with asthma by Young et al, using the multiple inert gas infusion technique. ${ }^{22}$ All subjects developed bronchoconstriction and impairment of gas exchange, shown as an increase in the dispersion of $\dot{V A} / Q$ values. Maximum changes were seen 15-30 minutes after exercise with recovery to pre-exercise values by 60 minutes. Two subjects developed a transitory bimodal $\dot{V} A / Q$ pattern with a low $\dot{V} A / Q$ mode, indicating the presence of lung units with completely obstructed bronchi, ventilation being maintained by collateral airflow. A similar study by Freyschuss et $a l^{23}$ showed varying degrees of bronchoconstriction and hypoxaemia after exercise in seven of 11 children with asthma; a bimodal $\dot{V}_{A} / Q$ distribution developed in six subjects, due in this case to the appearance of a high $\dot{V}_{A} / Q$ mode. Hypoxaemia was attributed to an increase in blood flow to lung units with $\dot{V}_{A} / Q$ ratios at the lower end of the normal range.

Values for $\mathrm{VD} / \mathrm{VT}_{\mathrm{T}}$ before and during exercise were within normal limits for most subjects, indicating that only a small proportion of lung units were overventilated in relation to their blood flow (or underperfused in relation to their ventilation). Negative values for $V D / V T$ were recorded during exercise in three subjects, as have been recorded previously in both normal ${ }^{24}$ and asthmatic subjects. ${ }^{1825}$ Possible explanations for a negative $\mathrm{VD} / \mathrm{VT}$ value include measurement error (especially for $\mathrm{PaCO}_{2}$ in capillary blood ${ }^{26}$ ), failure to allow for the rise in body core temperature that occurs during exercise (causing $\mathrm{PaCO}_{2}$ to be underestimated $)^{24}$; and failure to measure $\mathrm{PaCO}_{2}$ and $\mathrm{PECO}_{2}$ at the same time.

We wished the study to be of practical relevance and aimed therefore at a level of exercise that would approximate to the maximum most patients were likely to undertake while recovering from acute asthma. The external work load we used was that recommended for moderate exercise in normal subjects. ${ }^{27}$ This meant that subjects performed work at about $50 \%$ of their maximum exercise capacity, measured in terms of $\dot{\mathrm{VO}}_{2}$. We used constant load exercise rather than progressive exercise, to enable gas exchange to be measured during steady state conditions. Treatment was not withdrawn so that patients were studied under conditions that would normally apply to those who had recently been treated in hospital for acute asthma.

This study shows that in young patients given intensive treatment for a recent episode of acute severe asthma mild to moderate exercise is unlikely to cause a deterioration in gas exchange during or after exercise if resting measurements of PEF, $\mathrm{PaO}_{2}$, and $\mathrm{A}-\mathrm{aDO} \mathrm{O}_{2}$ are normal or near normal. Such patients can safely resume moderate exercise soon after being discharged from hospital.

GEP was supported by a grant from the Asthma Research Council. We thank Dr P S Burge and Dr J G Ayres for allowing us to study patients under their care. 
1 McFadden ER, Kiser R, DeGroot WJ. Acute bronchial asthma. N Engl J Med 1973;288:221-5.

2 Roca J, Ramis L, Rodriguez-Roisin R, Ballester E, Montserrat JM. Serial relationships between ventilationperfusion inequality and spirometry in acute severe perfusion inequality and spirometry in acute severe
asthma requiring hospitalisation. Am Rev Respir Dis asthma requiring

3 Rees HA, Millar JS, Donald KW. A study of the clinical course and arterial blood gas tensions of patients in status asthmaticus. QJ Med 1968;37:542-61.

$4 \mathrm{McFadden}$ ER. The chronicity of acute attacks of asthma mechanical and therapeutic implications. J Allergy Clin Immunol 1975;56:18-26.

5 Godfrey S. Exercise-induced asthma. In: Clark TJH Godfrey S, eds. Asthma 2nd ed. London: Chapman and Hall, 1983:57-78.

6 Wright BM, McKerrow CB. Maximum forced expiratory flow rate as a measure of ventilatory capacity with description of a new portable instrument for measuring it. Br Med J 1959;ii:1041-7.

7 European Community for Coal and Steel Working Party. Standardised lung function testing. Bull Eur Physiopatho Respir 1983;19(suppl 5):1-95.

8 Jones NL, Campbell EJM. Clinical exercise testing 2nd ed. London: Saunders, 1982:249.

9 Spiro SG, Dowdeswell IRG. Arterialised ear lobe blood samples for blood gas tensions. Br J Dis Chest 1976;80 263-8.

10 Campbell EJM. Burns Amberson Lecture. The management of acute respiratory failure in chronic bronchitis and emphysema. Am Rev Respir Dis 1967;96:626-39.

11 Cotes JE. Lung function: principles and application in medicine. 4th ed. London: Blackwejl Publications,

12 Enghoff $\mathrm{H}$. Volumen inefficax bermerkungen zur Frage des schadlichen Raumes. Ups Läkarfören Förhand 1938;44 191-218

13 Cole $\mathrm{RB}$, Bishop JM. Effect of varying inspired $\mathrm{O}_{2}$ tension on alveolar-arterial $\mathrm{O}_{2}$ tension difference in man. $J$ Appl Physiol 1963;18:1043-8.

14 Harries EA, Kenyon AM, Nisbet HD, Seeleye ER, Whitlock
RML. The normal alveolar-arterial oxygen tension gradient in man. Clin Sci 1974;46:89-104.

15 Malmberg F, Hedenström H, Fridriksson HV, Reference values for gas exchange during exercise in healthy nonvalues for gas exchange during exercise in healthy nonsmoking and smo

16 Jenkins PF, Benfield GFA, Smith AP. Predicting recovery from acute severe asthma. Thorax 1981;36:835-41.

17 Wagner PD, Dantzker DR, Iacovoni VE, Tomlin WC, West $\mathrm{JB}$. Ventilation perfusion inequality in asymptomatic asthma. Am Rev Respir Dis 1978;118:511-24.

18 Anderson SD, Silverman M, Walker SR. Metabolic and ventilatory changes in asthmatic patients during and after exercise. Thorax 1972;27:718-25.

19 Levine G, Hounsley F, Macleod P, Macklem PT. Gas exchange abnormalities in mild bronchitis and asympexchange abnormalities in mild bronchitis and

20 Graff-Lonnevig V, Bevegard S, Eriksson BO. Ventilation and pulmonary gas exchange at rest and during exercise in boys with bronchial asthma. Eur J Respir Dis 1980;61 357-66.

21 Hughes JMB. Lung gas tensions and active regulation of ventilation perfusion ratios in health and disease. $B r J D$ is Chest 1975;69:153-70.

22 Young IH, Corte P, Schoeffel RE. Pattern and time course of ventilation-perfusion inequality in exercise-induced asthma. Am Rev Respir Dis 1982;125:304-11.

23 Freyschuss U, Hedlin G, Hedenstierna G. Ventilationperfusion relationships during exercise-induced asthma in children. Am Rev Respir Dis 1984;130:888-94.

24 Bradley CA, Harris EA, Seeleye ER, Whitlock RML. Gas exchange during exercise in healthy people. Clin Sci exchange during

25 Beaudry PH, Wise MB, Seely JE. Respiratory gas exchange at rest and during exercise in normal and asthmatic children. Am Rev Respir Dis 1967;95:248-54.

26 McEvoy JDS, Jones NL. Arterialised blood gases in exercise studies. Med Sci Sports 1975;7:312-5.

27 Åstrand P-O, Rodahl K. Textbook of work physiology. 2nd ed. London: McGraw-Hill, 1977:358. 